\title{
Research on the Mental Health Problems and the Construction of Educational Models of Higher Vocational College Students
}

\author{
Jing Zeng \\ Wuhan Technical College of Communications, Wuhan, 430065, China \\ 19058293@qq.com
}

Keywords: Vocational college students, Mental health problems, Educational model construction.

\begin{abstract}
The mental health status of vocational college students is alarming since their mental health is at a low level. With the development and transformation of economy and society, the situation is getting worse. This paper investigates the mental health status of first-year students in Wuhan Technical College of Communications and finds that the psychological problems are as follows: 1) The inferiority of vocational college students is significantly higher than that of undergraduates; 2) the degree of interpersonal sensitivity, depression and obsession-compulsion is higher; 3) loneliness, confusion and anxiety are intertwined. This study will explore the new ways of mental health education, combine with the characteristics of mental health education curriculum, actively innovate the curriculum system, pursue diversification in curriculum teaching mode and teaching method, and fully mobilize the enthusiasm of students to realize the educational effect of the course of college students' mental health education.
\end{abstract}

\section{Introduction}

Vocational college students as a special social group have unique psychological characteristics. [1]At the same time, due to the reality of vocational students' belonging to the bottom of our higher education which means vulnerable groups, they tend to have corresponding problems both in cognitive ability and psychological aspects. Compared with ordinary institutions of higher learning, vocational students have diversified characteristics, including ordinary high school graduates, as well as from secondary schools (general secondary or vocational secondary school), vocational high school and graduates from technical schools. [2] The diversity of students makes the mental health problems of students in vocational colleges more complicated, which the management and experts and scholars should pay enough attention. Higher vocational students have obvious psychological problems, mainly including anxiety, paranoia, obsessive-compulsive symptoms, psychosis, terror, depression and so on. [3] Their mental health is worrying, and most of the study finds that the mental health of vocational students in the overall is at low level, and with the economic and social transformation, it is getting worse.

\section{Mental health problems of vocational college students}

The first-year students in Wuhan Technical College of Communications were asked to do question answering test through the Internet, and SPSS was used to collect data for statistical analysis. Through the psychological data, all kinds of counseling and crisis intervention, the psychological status of vocational college students have the following characteristics.

\subsection{Psychological problems are increasing year by year}

The analysis shows that the proportion of the number of people who have general psychological problems in the group is increasing year by year. The Psychological symptom checklist (SCL-90) is 
one of the most famous mental health qualitative test scale in the world. It is also the most widely used mental disorders and mental illness outpatient examination scale, which is used to test the mental health situation. From the result, the proportion of students' psychological problems has increased from 15.6\% in 2012 to 23.8\% in 2016. Specific results are showed in Table 1.

Table 1 The average detection rate of psychological problems of vocational college students in recent years

\begin{tabular}{|c|c|}
\hline Years & $\begin{array}{c}\text { The proportion of psychological } \\
\text { problems }\end{array}$ \\
\hline 2012 & 15.6 \\
\hline 2013 & 17.4 \\
\hline 2014 & 19.5 \\
\hline 2015 & 21.6 \\
\hline 2016 & 23.8 \\
\hline
\end{tabular}

\subsection{Self-inferiority mentality of vocational students}

The self-inferiority mentality of vocational students was investigated through university personality inventory (UPI) and the results are showed in Table 2.

Table 2 "Lack of self-confidence” UPI Statistics of Students in Hubei University and Wuhan Technical College of Communications

\begin{tabular}{|c|c|c|}
\hline Items & $\begin{array}{c}\text { Rate of students in } \\
\text { Hubei University(\%) }\end{array}$ & $\begin{array}{c}\text { Rate of students in Wuhan Technical } \\
\text { College of Communications(\%) }\end{array}$ \\
\hline Too dependent on others & 17.23 & 18.48 \\
\hline Feel inferior & 14.82 & 16.32 \\
\hline Lack courage to do things & 9.38 & 13.48 \\
\hline The realization of others & 8.49 & 12.89 \\
\hline Lack decision-making ability & 20.12 & 33.08 \\
\hline Lack confidence & 22.09 & 32.97 \\
\hline Pay too much attention to other people & 45.78 & 27.65 \\
\hline Parents expect too high & 18.39 & 29.17 \\
\hline Too rigid & 17.28 & 23.63 \\
\hline
\end{tabular}

From the table 2, it is obvious that the level of self-inferiority of vocational students is higher than that of undergraduate students. The survey selected "lack of self-confidence" as the title, including a total of nine items, and the results show that in all the nine items, the rates of vocational students are higher than that of the undergraduate students, in which the rates of vocational students in "Lack decision-making ability", "Parents expect too high", "Pay too much attention to other people" and other options are much higher than that of the undergraduates.

\subsection{Higher degree of interpersonal sensitivity, depression and obsession-compulsion}

According to the results of SCL-90 survey of self-rating scale, the comparative analysis showed that among the ten characteristic factors, the largest proportion was interpersonal sensitivity, which accounted for $61.25 \%$ of the factors. The next two item were depression and obsession-compulsion, accounting for $53.1 \%$ and $52.7 \%$ of the corresponding factors respectively. The other symptoms, anxiety, paranoia and hostility which are not so serious were $45.26 \%, 42.76 \%$, $26.1 \%$ and $43.1 \%$ respectively. The smallest proportion of psychological symptoms were psychosis, integration and fear, accounting for $36.8 \%$, 32.2\%, 26.1\% of the corresponding factors respectively. This shows that vocational students have the most serious psychological problems in interpersonal sensitivity, depression and obsession-compulsion.

\subsection{Loneliness, confusion and anxiety are intertwined}

Specific performance is: (1) lack of learning initiative. Compared with the ordinary institutions of higher learning students, students in vocational colleges are more intended to leave early, skip 
homework, be late, skip class, sleep in class and so on; (2) self-centeredness and blind conformity. In contrast, students in vocational colleges lack the awareness and spirit of cooperation in learning or living, and lack the depth of communication and discussion on social and life issues. In the behavior orientation, they tend to follow the mass media and the behavior of surrounding groups; (3) often ignore the social norms.

\section{Construction of the Educational Model for the Psychological Problems of Higher Vocational College Students}

According to the actual situation of higher vocational colleges, we have learned from the practice of mental health education in foreign schools and have built a typical mental health education model, as shown in the figure 1. The characteristics of this model are from six aspects, and each aspect advances from three levels. [4] And this model puts forward three major goals of mental health education for vocational students: psychological diagnosis and treatment goals, psychological preventive goals and psychological development educational goals from mental health education system build three health care systems of school, faculties and class; from the implementation platform, there are school curriculum education, school culture and extracurricular activities platform; from the level of mental health education, it is divided into mental unhealthy, sub-healthy and healthy three different psychological levels; from the perspective of rapid crisis intervention institutions, it is divided into: school psychological counseling center, school psychological education management group and social professional mental health institutions; from the perspective of resources, family, society and school have tripartite linkage.

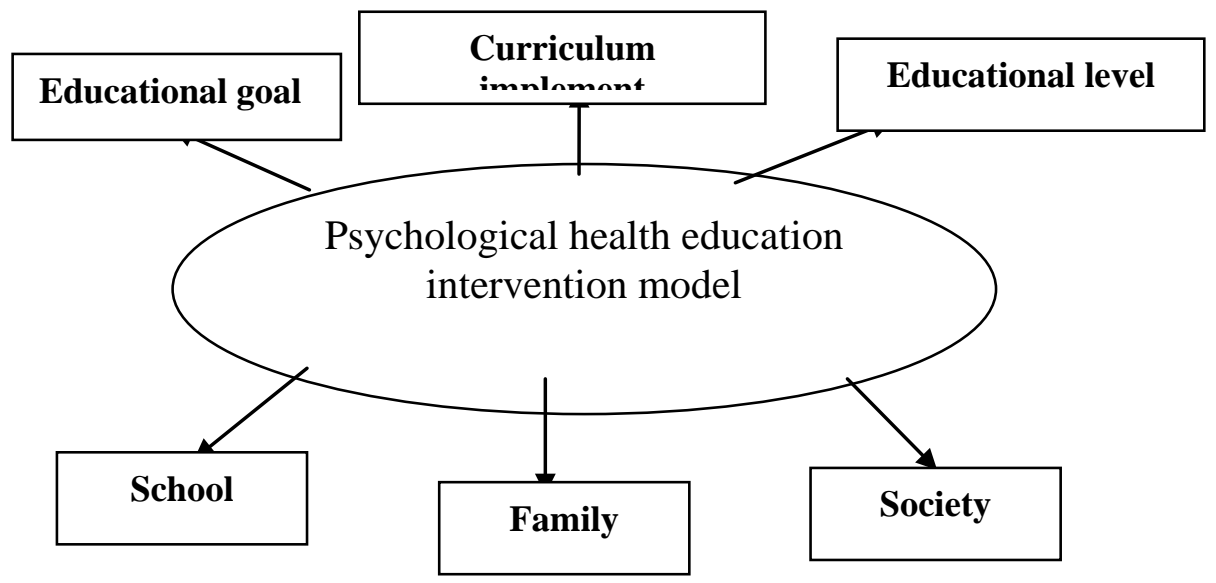

Figure 1 Psychological health education intervention model

\subsection{Promote the mental health of college students with positive psychological intervention and counseling}

The psychological counseling in colleges and universities focus on the psychological problems of students to eliminate the psychological confusion and psychological diagnosis of the disease, but from the consultation situation, due to poor psychological ability of students, counseling can only meet their psychological needs at that time, so when they encounter new problems, they will rely on psychological counseling again and can not do self-adjustment. Positive psychology thinks that, in order to really play a preventive effect of psychological problems, we can not only focus on the existence of individual weaknesses or defects, but should discover more individual's own active power to adjust individual's inner balance, so as to achieve the prevention of psychological problems and the treatment of psychological disorders and diseases. [5]Positive psychology guides people from two aspects to seek positive meaning, one is to find out the root causes of their own problems, and the other is based on the problem itself to find a positive individual experience, to cultivate and enhance the individual's own positive power to confront the negative problems. It is mainly taken to tap the individual's own personality and other positive factors, for example, in the 
process of resisting individual mental disorders or diseases, hope and optimism, positive self and so on are the best medicine.

\subsection{Create a positive university campus environment}

First of all, a multi-platform should be provided to enhance students' positive experience and positive emotions. Healthy and useful cultural and sports activities should be organized to create a positive, relaxed and harmonious campus atmosphere. The college can set up various associations, salons, etc., so that students have the opportunity to meet like-minded friends, to promote their communication and get practiced in the collective activities. Secondly, through the integration and use of community libraries, exhibition halls, patriotism education base, a variety of mental health education and training sites and other places, students can be regularly organized to carry out training and psychological counseling activities. This can promote students to love and feel life better, so as to develop a healthy personality. At the same time the school can create a healthy atmosphere conducive to college students by actively using the campus radio station, campus television, campus network, school newspaper, window, blackboard report and other school media and mental health education publications and mental health education website.

\subsection{Establish a contingent of high-quality psychological teachers}

Colleges and universities must establish a contingent of high-quality psychological teachers. Firstly, we should put some teachers who are keen on mental health education with the relevant professional basis of the teacher into the mental health education team and improve their business ability and professional level through training. We should establish a high level, relatively stable, high quality of college mental health education teachers and strive to create a positive atmosphere of mental health education, so that each teacher can take the task of mental health education. Secondly, we should strictly implement the mental health education teacher qualification system. Mental health education is a highly professional work, and the professional quality of mental health education teachers will have certain physical and mental impact on students, besides, the implementation of health education courses also depends on the mental health education practitioners. In order to improve the effect of mental health education curriculum, we must take practical measures to ensure the good quality of mental health teachers. Only people who are qualified by the assessment of mental health education can be appointed as mental health education teachers to ensure the quality of teachers.

\subsection{Build a positive student self-help system}

Higher vocational colleges can fully use students' own strength, build students' psychological self-help system and give mental health education, to achieve the purpose of student self-help and mutual assistance. The establishment of self-help system can make students more concerned about mental health problems, strengthen the publicity of psychological knowledge, establish the correct concept and positively face the mental health problems. Students mental health self-help system is divided into three forms: firstly, build the college students psychological counseling center or mental health teaching and research section under the name of student work department or school youth corps committee. And then under the guidance, student organizations of mental health education can be built to help mental health education activities for whole students; next, each department can develop its own students psychological department organized by the students to help students to develop the mental health education activities and also can develop psychological salon and other activities be based on the department's professional characteristics. Finally, each class as a unit, through the voluntary enrollment of students, counselors can choose loving students with good psychological quality to form a psychological growth group in class. 


\section{Conclusion}

Based on the analysis of the present situation of mental health education in vocational colleges in our country, this paper makes an in-depth analysis of the problems existing in the mental health education of vocational students. The following problems are found in the current mental health education. At the same time, the author analyzes the causes of the problems of college students' mental health education in our country. Finally, the author puts forward the educational model to solve the problem of mental health of vocational college students and gives the relevant solutions in a corresponding way, aiming at the early detection and early intervention of the mental health problems of vocational college students. This study clarifies the goal of mental health education for vocational college students and explores the diverse ways of college students' mental health education.

\section{Acknowledgements}

In this paper, the research was sponsored by Teaching and Researching Project of Hubei Province (Project No. 2016322)

\section{References}

[1]A multifactor approach to student model evaluation[J] . Michael V. Yudelson, Olga P. Medvedeva, Rebecca S. Crowley. User Modeling and User-Adapted Interaction. 2008 (4)

[2]Measuring quality in higher education: A competency approach. J. Warn,P. Tranter. Quality in Higher Education . 2001

[3]School psychology goes to college: The emerging role of school psychology in college communities[J] . Michael L. Sulkowski,Diana J. Joyce. Psychol. Schs. . 2012 (8)

[4]Spirituality in Indian University Students and its Associations with Socioeconomic Status, Religious Background, Social Support, and Mental Health[J]. Sibnath Deb,Kevin McGirr,Jiandong Sun. Journal of Religion and Health. 2016(5)

[5]Relationship between psychological inflexibility and experiential avoidance and internet addiction: Mediating effects of mental health problems[J]. Wei-Po Chou,Kun-Hua Lee,Chih-Hung Ko,Tai-Ling Liu,Ray C. Hsiao,Hsiu-Fen Lin,Cheng-Fang Yen. Psychiatry Research. 